\title{
Postmortem estimation of temperature distribution on a power transformer: Physicochemical and Mechanical approaches
}

\author{
Juan Carcedo ${ }^{1}$, Inmaculada Fernández ${ }^{1}$, Alfredo $_{\text {Ortiz }^{1}}\left({ }^{*}\right)$, Isidro Carrascal ${ }^{2}$, Fernando Delgado $^{1}$, Alberto \\ Arroyo $^{1}$ \\ University of Cantabria \\ Avenida de Los Castros \\ 39005, Santander. Cantabria (Spain) \\ ${ }^{1}$ Electrical and Energy Engineering Department \\ ${ }^{1}$ E.T.S. de Ingenieros Industriales y de Telecomunicación \\ ${ }^{2}$ Laboratory of the Science and Engineering of Materials \\ ${ }^{2}$ E.T.S. de Ingenieros de Caminos, Canales y Puertos.
}

(*) Corresponding Author Contact Details:

Tel: +34942201374-+34626966431

Fax: +34 942201385

ortizfa@unican.es

\section{Introduction}

Transformers are one of the most expensive and critical components of electric energy transmission and generation systems [1]. Although transformers are very reliable machines a failure is possible at any age due to many factors as incorrect specification or operation, design or manufacturing errors, bad maintenance, excessive ageing...[2, 3, 4]. Therefore knowing transformers condition is essential to manage large networks [5, 3].

The transformers' life span is determined amongst other parameters by the condition of the solid insulation, particularly at the hot spot [6]. The primary solid insulation used in liquid filled power transformers is cellulose [6]. The cellulose which is composed of polymerized glucose molecules suffers degradation due to thermal stress caused by electric load losses in the transformer, moisture, oxygen, contamination from conducting particles and mechanical damage or weakening from vibration [7]. The three main processes for cellulose degradation are hydrolysis, oxidation, and pyrolysis [8-10]. Hydrolysis involves water and acids, which break the cellulose polymer chain. Oxygen dissolved in the oil accelerates the rate of aging of paper. Pyrolysis is decomposition occurring at temperatures above $140^{\circ} \mathrm{C}$. Transformer paper operating under normal or overload conditions does not reach this temperature unless a fault develops. The products of cellulose degradation are carbon monoxide $(\mathrm{CO})$, carbon dioxide $\left(\mathrm{CO}_{2}\right)$, organic acids, water and free glucose molecules. The glucose rings can decompose further into furans [11].

These degradation by-products are soluble in transformer oil. For this reason, analysis of the oil for the degradation by-products (water, dissolved gases, furans) have been used to determine the degree of aging of the cellulose insulation [12-14]. Nevertheless, these techniques are macro in respect to the entire insulation system where may exist a significant thermal gradient [6]. The hot-spot temperature is one of the most critical parameter to estimate the remaining lifetime of solid insulation $[4,5]$. This temperature can be estimated trough thermal model of a transformer taking into account the loading profile of the system, the ambient temperature profile over the year and the setting of the thermostatically controlled cooling system [3, 15-20]. Other method to determine this hot-spot temperature is taking paper samples from representative parts of the windings and analysing for degree of polymerisation (DP) which is a valid indicator of paper ageing with a value of 200 taken as end of life [2, 21]. It measures the average chain length of the cellulose molecules. However, it is not possible to obtain paper samples from a transformer in service. The DP determination is only possible when a transformer has been removed from service and a detailed postmortem investigation of the solid insulation is performed [6].

Different authors have carried out a procedure in which paper samples are taken and tested for DP to obtain a map of the solid insulation aging [5-6, 22-26]. For instance, Koch et al. investigated new approaches to determine water in oil-paper-insulated power transformers to conform diagnostic 
parameters to postmortem investigations as well as, correlations between the furan (2-FAL) concentration in the oil and the average DP [10,23-24]. Their aim was to close the gap between the findings during the visual inspection of the active part just before scrapping, the results of the material analysis and parameters which can easily be measured during the life time of the transformer such as water, dissolved gas analysis (DGA) and furanes. Susa et al. carried out the condition assessment of a generator transformer by the mapping of degree of polymerization (DP). They also showed the temperature mapping, where the temperature estimation was based on the paper aging kinetics, transformer loading and insulation operating history. Finally, they gave a new equation for the relative aging rate considering all insulation conditions providing possibility of counting transformer loss-of-life more accurately $[5,26]$. Prevost et al. also carried out a forensic analysis because the oil analysis had not yield a clear picture of a possible problem in two transformers [6]. Other situation where accurate paper degradation diagnostic could be useful was described by Martins et al. [25]. At the end of 2007, and after a network rearrangement in a region of Portugal, the Pracana substation became redundant. These authors performed a condition evaluation of a transformer to make a decision regarding its transfer to a new substation located in the same region. They carried out a diagnostic based on oil analysis and measures of DP and compared them.

The combination of the results from service history and postmortem analysis from scrapped and failed transformers help to discover design and material problems specific to a family of transformers which were designed for a specific application and have the same size, voltage class, winding style and cooling system.

All these postmortem studies have been based on DP which constitutes one of the most important parameters of the insulation condition [2]. The chain length of the cellulose molecules determines the mechanical strength of insulation with cellulose materials. The mechanical strength of the cellulose fibers weakens continuously due to the degradation cellulose's [27, 28]. Moser et al. established that both tensile strength index and DP decrease exponentially during ageing at constant temperature [29] Therefore, it is possible evaluate the aging of paper through the tensile strength index. In this work paper samples were taken from a failed distribution transformer to determine DP and tensile strength index (TS). Later, the distribution temperature was obtained through DP and TS results. The two temperature distributions were compared in order to show the suitability of tensile analysis for a postmortem study. The main reason to use tensile strength index instead of DP is that the first one could be carried out more quickly. Additionally, TS test is much more reliable than DP test. This new approach can serve to obtain additional information about the cause of the turn-to-turn shortcircuit fault suffered by this transformer.

\section{Transformer description}

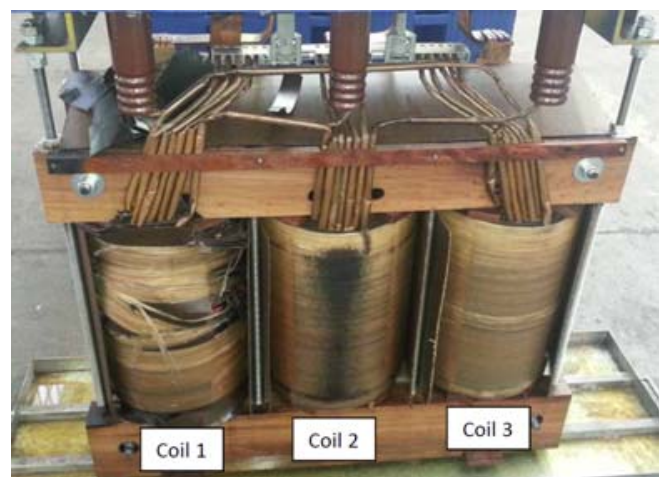

Fig. 1. Transformer studied: State of the three windings.

The tests were conducted using the isolation paper of a three-phase transformer with a rated power of $800 \mathrm{kVA}$ at $50 \mathrm{~Hz}$ and manufactured in 1986 with a ONAN cooling system. The total weight of the transformer is $2130 \mathrm{~kg}$, with a mass of liquid insulating equal to $390 \mathrm{~kg}$. The connection of the transformer windings is Dy11 type, with a voltage ratio $30.000 / 400 \mathrm{~V}$.

The transformer suffered a short circuit between turns in one of the coils and had to be withdrawn from service after 26 years of operation. This type of distribution transformers are not monitored, so there are no measures that indicate the progress of the dielectric system degradation. Fig. 1 shows the damage that the fault causes in the transformer. 


\section{Methodology to obtain temperature distribution into the transformer}

This work has followed the methodology shown in Fig. 2 in order to demonstrate the suitability of TS for temperature distribution evaluation in postmortem studies:

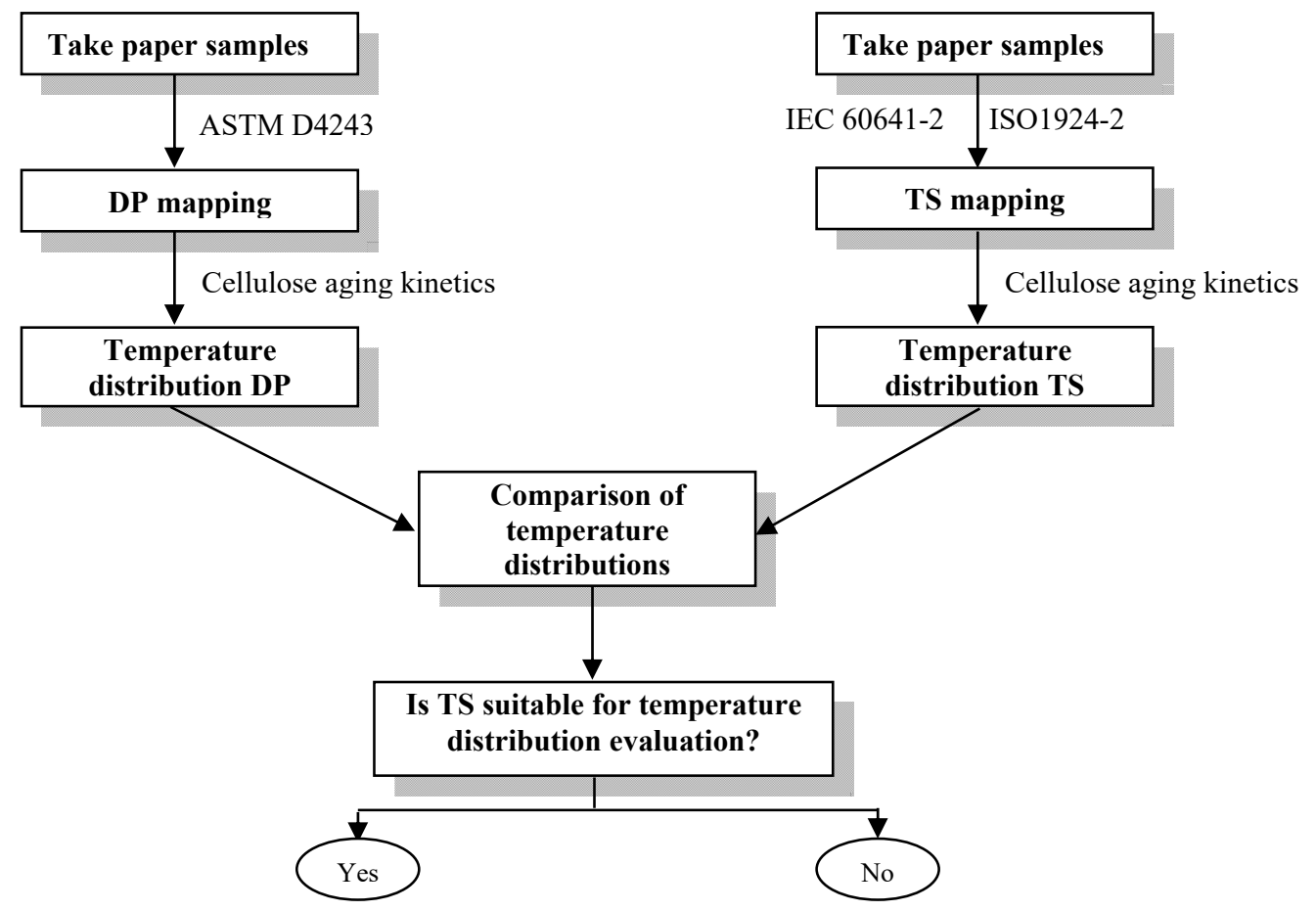

Fig. 2. Methodology applied in this work.

\section{1.- Samples collection}

Each coil has a height of $50 \mathrm{~cm}$ and paper samples were taken at different heights in order to calculate the tensile index and the degree of polymerization. This allowed us to observe the degradation distribution along the coils. In Fig. 3, the two layers of paper for insulating the phases can be observed, inner and outer strips. Paper samples were taken from both layers and were analyzed during the tests to see their real state. In Table 1 below, the heights of the points at which the paper samples were taken from the coils for further analysis are recorded. el means that the sample comes from the outer strip of paper. e2 means that the sample comes from the inner strip of paper.

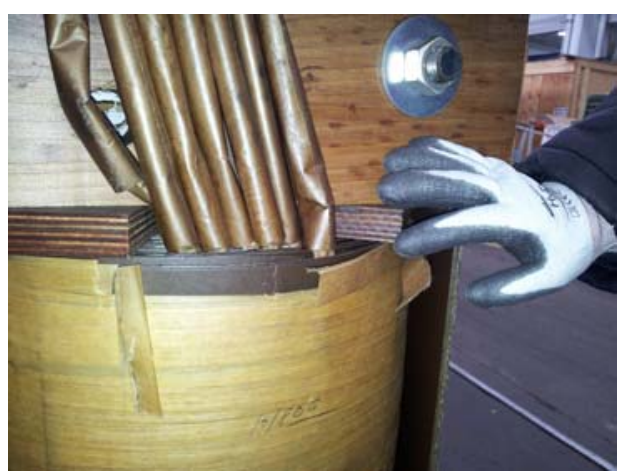

Fig. 3. Transformer studied: Detail of the inner and outer paper layers.

Table 1

Samples analyzed: height, coil number and type of layer. 


\begin{tabular}{|c|c|c|c|}
\hline Sample & Height (cm) & Coil & $\begin{array}{c}\text { Outer layer (e1), } \\
\text { Inner layer(e2) }\end{array}$ \\
\hline 1 & 50 & 3 & e1_1 \\
\hline 2 & 50 & 3 & e2_1 \\
\hline 3 & 40 & 3 & e1_2 \\
\hline 4 & 40 & 3 & e2_2 \\
\hline 5 & 30 & 3 & e1-3 \\
\hline 6 & 30 & 3 & e2_3 \\
\hline 7 & 19 & 3 & e1_4 \\
\hline 8 & 19 & 3 & e2_4 \\
\hline 9 & 10 & 3 & $\mathrm{e}^{-} 5$ \\
\hline 10 & 10 & 3 & e2_5 \\
\hline 11 & 2 & 3 & e1_6 \\
\hline 12 & 2 & 3 & e2_6 \\
\hline 13 & 50 & 2 & e1_7 \\
\hline 14 & 50 & 2 & e2_7 \\
\hline 15 & 40 & 2 & e1_8 \\
\hline 16 & 40 & 2 & e2_8 \\
\hline 17 & 30 & 2 & e1-9 \\
\hline 18 & 30 & 2 & e2_9 \\
\hline 19 & 20 & 2 & e1 10 \\
\hline 20 & 20 & 2 & e2-10 \\
\hline 21 & 10 & 2 & e1_11 \\
\hline 22 & 10 & 2 & e2-11 \\
\hline 23 & 0 & 2 & e1_12 \\
\hline 24 & 0 & 2 & e2_12 \\
\hline 25 & 10 & 1 & e1_13 \\
\hline 26 & 10 & 1 & e2_13 \\
\hline 27 & 5 & 1 & e1_14 \\
\hline 28 & 5 & 1 & e2_14 \\
\hline 29 & 45 & 1 & e1_15 \\
\hline 30 & 45 & 1 & e2 15 \\
\hline
\end{tabular}

\section{2.- DP and TS mapping}

Once paper samples were collected, in the next step DP and TS values were measured in accordance with ASTM D4243, IEC 60641-2 and ISO1924-2 [30-32].

The ASTM D4243 test method describes a standard procedure for determining the average viscometric degree of polymerization (abbreviated $\mathrm{DP}_{\mathrm{v}}$ ) of new or aged electrical papers. The determination is made by measuring the intrinsic viscosity of a solution of the paper in an appropriate solvent (cupriethylenediamine). The degree of polymerization (or the degree of condensation) of a particular cellulose molecule is the number of anhydro-b-glucose monomers, $\mathrm{C}_{6} \mathrm{H}_{10} \mathrm{O}_{5}$, in the cellulose molecule.

In IEC60641-2 the tests methods for pressboard and presspaper for electrical purposes are described. ISO1924-2 details the determination of tensile properties of paper. Tensile force is measured under standardized test conditions to cause failure of test pieces $15 \mathrm{~mm} \times 250 \mathrm{~mm}$ cut from both directions of the material. This value represents quite well the current state of paper samples. The tensile strength index, in $\mathrm{kN} \mathrm{m} / \mathrm{kg}$, is calculated by the formula: $T S=F /(w x b)$. Where $F$ is the force, in $\mathrm{kN}$; $\mathrm{b}$ is the width of the specimen, in $\mathrm{m}$; and $w$ is the grammage of the specimen, in $\mathrm{kg} / \mathrm{m}^{2}$.

\section{3.- Temperature distribution}

Once DP and TS results have been obtained the temperature distributions were estimated through cellulose kinetics. Different authors have reported the relationship between DP, time and temperature [13, 27]. In this work, it has been considered the relationship defined by Heywood [33] who suggested that the rate of change of DP can be represented by:

$$
\frac{1}{D P_{t}}-\frac{1}{D P_{0}}=\frac{k_{1_{0}}}{k_{2}} *\left[1-e^{-k_{2}{ }^{*} t}\right]
$$


where $\mathrm{k}_{10}$ is the initial rate at which bonds break, $\mathrm{k}_{2}$ is the rate at which $\mathrm{k}_{10}$ changes, $\mathrm{DP}_{\mathrm{t}}$ is the insulation $\mathrm{DP}$ value at time $\mathrm{t}, \mathrm{DP}_{0}$ is the initial insulation $\mathrm{DP}$ value and $\mathrm{t}$ is the time in hours.

Heywood also proposed in his thesis a model which relates the average chain length (DP) with the fibre strength:

$T S_{t}-T S_{0}=K_{1} * e^{-k_{2}{ }^{*} t}+K_{2} *\left(\ln \left(e^{k_{2} * t}-K_{3}\right)\right)-K_{4}$

Where

$$
\begin{aligned}
& K_{1}=\frac{k_{3} * k_{1_{0}}}{k_{2}} \\
& K_{2}=k_{4} * K^{\prime} \\
& K_{3}=k_{1_{0}} * K^{\prime} \\
& K_{4}=K_{2} *\left(\ln \left(1-K_{3}\right)\right)+K_{1} \\
& K^{\prime}=\frac{D P_{0}}{D P_{0} * k_{1_{0}}+k_{2}}
\end{aligned}
$$

$\mathrm{TS}_{\mathrm{t}}$ is the insulation tensile strength index value at time $\mathrm{t}, \mathrm{TS}_{0}$ is the initial insulation tensile strength index value and $t$ is the time in hours.

Assuming that the Arrhenius equation is valid from the normal operating temperature of power transformers up to the temperatures used in aging experiments [27], the constants $\mathrm{k}_{10}, \mathrm{k}_{2}, \mathrm{k}_{3}$, and $\mathrm{k}_{4}$ can be obtained by applying the following equation:

$$
k=A^{*} e^{-\frac{E_{a}}{R^{*} T}}
$$

where

$\mathrm{k}$ : rate constant

A: pre-exponential factor

$\mathrm{E}_{\mathrm{a}}$ : activation energy

$\mathrm{R}$ : molar gas constant $\left(8.314 \mathrm{JK}^{-1} \mathrm{~mol}^{-1}\right)$

$\mathrm{T}$ : temperature in Kelvin

Knowing the values of activation energy $\left(E_{a}\right)$ and pre-exponential factor $(A)$, obtained through accelerated aging experiments performed in the laboratory, it is possible to calculate the constants $\mathrm{k}_{10}, \mathrm{k}_{2}$, $\mathrm{k}_{3}$, and $\mathrm{k}_{4}$.

Table 2

Arrhenius parameters for Kraft paper in oil.

\begin{tabular}{ccc} 
& $\mathbf{E}_{\mathbf{a}}(\mathbf{J} / \mathbf{m o l})$ & $\mathbf{A}\left(\mathbf{h}^{-\mathbf{1}}\right)$ \\
\hline $\mathrm{k}_{10}$ & 115200 & $9.10^{*} 10^{8}$ \\
$\mathrm{k}_{2}$ & 126900 & $3.06^{*} 10^{12}$ \\
$\mathrm{k}_{3}$ & -43700 & $7.82 * 10^{-2}$ \\
$\mathrm{k}_{4}$ & $5.54 * 10^{-2}$ & $1.60^{*} 10^{-6}$ \\
\hline
\end{tabular}

In order to estimate the temperature distributions, samples of new paper has been analysed, determining that $\mathrm{DP}_{0}$ and $\mathrm{TS}_{0}$ values were 1257 and $553(\mathrm{kN} / \mathrm{mKg})$, respectively. Taking into account the date in which the transformer was connected to the distribution network, the total period of operation considered is 227760 hours so, $t=227760 \mathrm{~h}$. The data obtained on the mapping stage for each sample give $\mathrm{DP}_{\mathrm{t}}$ and 
$\mathrm{TS}_{\mathrm{t}}$. With all these data and the Eqs. (1)-(2) the temperature distribution on each coil of the transformer can be obtained. In the next section of this paper a comparison between these results is performed.

\section{Results}

With the paper samples taken from the three coils of the transformer, the degree of polymerization (DP) was analysed in a viscometric environment, following the ASTM D4243 standard, as it was already explained above. The summary of the results obtained for the DP in each winding of the transformer is shown in Table 3. As seen in this table, the values of DP range from 276.9 to 364.4. The results reported in the table show that the degree of aging along the entire height of the coil is quite homogeneous. Similarly, one can also observe that the deterioration of the paper is similar in both the inner and the outer layer, although overall deterioration of the inner layer is somewhat less than the outer layer.

In like manner, the paper samples of the three transformer coils were analysed by obtaining the tensile strength index (TS), according to the ISO1924-2 standard, as already explained above. The summary of the results obtained for the tensile index are shown in Table 3. TS values range from 227.1 to 326.2. These results showed that, like the DP map, aging along the entire height of the coil is quite similar. Unlike what happened in the map of DP in the case of TS exists higher deterioration at $10 \mathrm{~cm}$ in almost all coils. Moreover, from the TS point of view, there are no clear differences between the outer and the inner strips, except at the coil that suffered the short circuit.

From DP and TS maps, the temperature distribution throughout the transformer windings was estimated using Eqs. (1)-(2). In Figs. 4-9, the estimated temperatures for each point are shown, considering the two methodologies, differentiating each coil and the inner from the outer layer.

In the coil 1, where the short-circuit appeared, the greatest differences between the temperature estimate performed by both methods are seen, these being reasonably low. The estimate carried out by the DP method provides lower values for all points in the inner layer and for two of the three points analysed in the outer one. In the samples taken at 10 and $45 \mathrm{~cm}$, the highest differentials are shown with $3.3 \mathrm{~K}$ and $2.1 \mathrm{~K}$, respectively. In the coil 2 the two methods are closer than in the previous case, differences varying between $1.3 \mathrm{~K}$ and $0.018 \mathrm{~K}$. The coil 3 also shows similar temperature distributions for both methodologies, fluctuating between $1.9 \mathrm{~K}$ and $0.2 \mathrm{~K}$.

The maximum temperature estimated from DP in the windings is $358.5 \mathrm{~K}$. And the temperature profile obtained from the tensile index shows that the highest temperature in the surface of the coils is $358.2 \mathrm{~K}$, which is slightly lower than the maximum temperature obtained from the map of DP. These maximum temperatures represent the most unfavourable conditions on the high voltage winding surface. 
Table 3

Determination of DP and TS.

\begin{tabular}{|c|c|c|c|c|c|c|c|c|}
\hline Sample & $\begin{array}{l}\text { Eflux time of the } \\
\text { solution (s) }\end{array}$ & $\begin{array}{c}\text { Specific } \\
\text { viscosity } \\
{\left[\eta_{\mathrm{s}}\right]}\end{array}$ & $\begin{array}{l}\text { Concentration } \\
{[\mathbf{c}](\mathrm{g} / \mathrm{dl})}\end{array}$ & {$[\eta] * c$} & $\begin{array}{c}\text { Intrinsic } \\
\text { viscosity }[\eta]\end{array}$ & $\begin{array}{c}\text { Degree of } \\
\text { polymerization }[\mathrm{DP}]\end{array}$ & $\begin{array}{l}\text { Grammage } \\
\qquad\left(\mathrm{kg} / \mathrm{m}^{2}\right)\end{array}$ & $\begin{array}{l}\text { Tensile index } \\
(\mathrm{kNm} / \mathrm{Kg})\end{array}$ \\
\hline 1 & 203.46 & 0.41 & 0.16 & 0.36 & 2.32 & 309.37 & 0.12 & 282.37 \\
\hline 2 & 184.52 & 0.28 & 0.12 & 0.25 & 2.15 & 286.69 & 0.12 & 279.82 \\
\hline 3 & 192.08 & 0.33 & 0.14 & 0.30 & 2.12 & 282.40 & 0.12 & 273.17 \\
\hline 4 & 194.00 & 0.34 & 0.13 & 0.31 & 2.44 & 325.81 & 0.12 & 276.97 \\
\hline 5 & 193.13 & 0.33 & 0.14 & 0.30 & 2.18 & 290.40 & 0.12 & 275.50 \\
\hline 6 & 189.63 & 0.39 & 0.13 & 0.28 & 2.16 & 288.15 & 0.12 & 307.64 \\
\hline 7 & 187.02 & 0.29 & 0.13 & 0.27 & 2.08 & 276.93 & 0.12 & 283.27 \\
\hline 8 & 184.10 & 0.27 & 0.11 & 0.25 & 2.31 & 307.33 & 0.12 & 261.83 \\
\hline 9 & 204.61 & 0.41 & 0.16 & 0.37 & 2.37 & 316.60 & 0.12 & 240.85 \\
\hline 10 & 179.12 & 0.24 & 0.09 & 0.22 & 2.35 & 313.86 & 0.12 & 227.29 \\
\hline 11 & 184.50 & 0.28 & 0.12 & 0.25 & 2.08 & 277.93 & 0.12 & 291.19 \\
\hline 12 & 193.21 & 0.34 & 0.12 & 0.30 & 2.45 & 326.80 & 0.12 & 285.88 \\
\hline 13 & 181.73 & 0.26 & 0.11 & 0.24 & 2.24 & 298.11 & 0.12 & 286.15 \\
\hline 14 & 168.57 & 0.16 & 0.07 & 0.16 & 2.15 & 286.48 & 0.12 & 239.03 \\
\hline 15 & 194.41 & 0.34 & 0.14 & 0.31 & 2.23 & 296.90 & 0.12 & 242.13 \\
\hline 16 & 179.20 & 0.24 & 0.10 & 0.22 & 2.23 & 297.09 & 0.12 & 281.01 \\
\hline 17 & 178.22 & 0.23 & 0.09 & 0.22 & 2.45 & 326.30 & 0.12 & 290.03 \\
\hline 18 & 176.13 & 0.22 & 0.10 & 0.20 & 2.10 & 279.70 & 0.12 & 270.11 \\
\hline 19 & 179.47 & 0.24 & 0.10 & 0.22 & 2.26 & 301.20 & 0.12 & 302.30 \\
\hline 20 & 184.25 & 0.27 & 0.10 & 0.25 & 2.66 & 354.40 & 0.12 & 292.91 \\
\hline 21 & 194.88 & 0.35 & 0.14 & 0.31 & 2.17 & 289.77 & 0.12 & 237.93 \\
\hline 22 & 186.23 & 0.29 & 0.12 & 0.26 & 2.23 & 297.73 & 0.12 & 290.14 \\
\hline 23 & 177.82 & 0.23 & 0.01 & 0.21 & 2.14 & 284.67 & 0.12 & 266.46 \\
\hline 24 & 180.22 & 0.25 & 0.09 & 0.23 & 2.53 & 336.80 & 0.12 & 286.57 \\
\hline 25 & 196.70 & 0.36 & 0.12 & 0.32 & 2.73 & 363.70 & 0.12 & 326.27 \\
\hline 26 & 198.87 & 0.37 & 0.12 & 0.34 & 2.71 & 361.87 & 0.12 & 227.17 \\
\hline 27 & 192.31 & 0.33 & 0.12 & 0.30 & 2.50 & 333.73 & 0.12 & 271.56 \\
\hline 28 & 179.19 & 0.24 & 0.08 & 0.22 & 2.73 & 364.40 & 0.12 & 283.31 \\
\hline 29 & 179.95 & 0.24 & 0.09 & 0.23 & 2.58 & 343.60 & 0.12 & 264.71 \\
\hline 30 & 181.73 & 0.26 & 0.01 & 0.24 & 2.25 & 300.53 & 0.12 & 263.28 \\
\hline
\end{tabular}




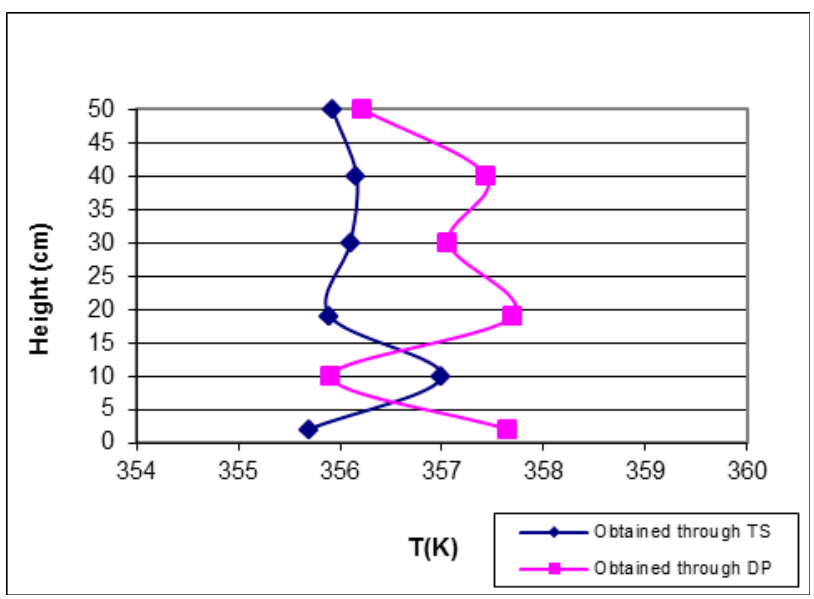

Fig. 4. Comparison of temperatures obtained through DP and TS (outer layer, coil 3).

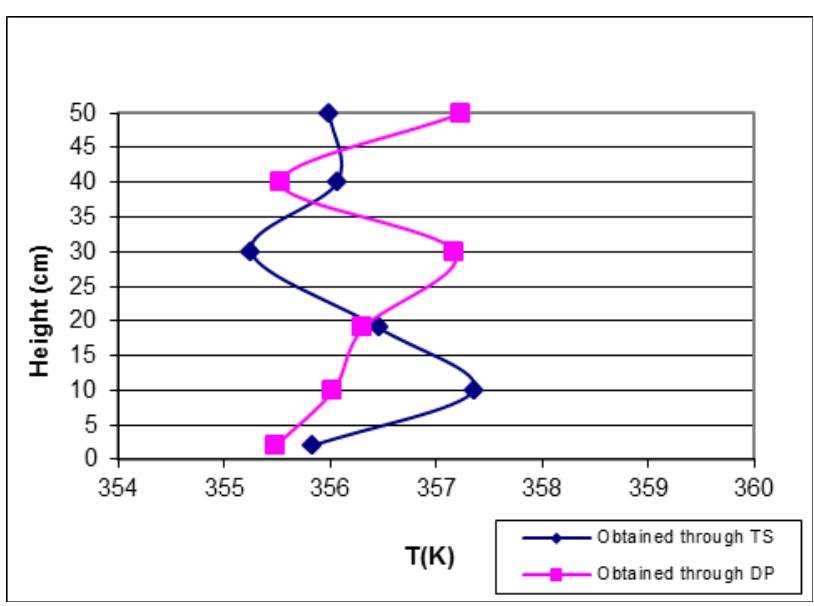

Fig. 5. Comparison of temperatures obtained through DP and TS (inner layer, coil 3).

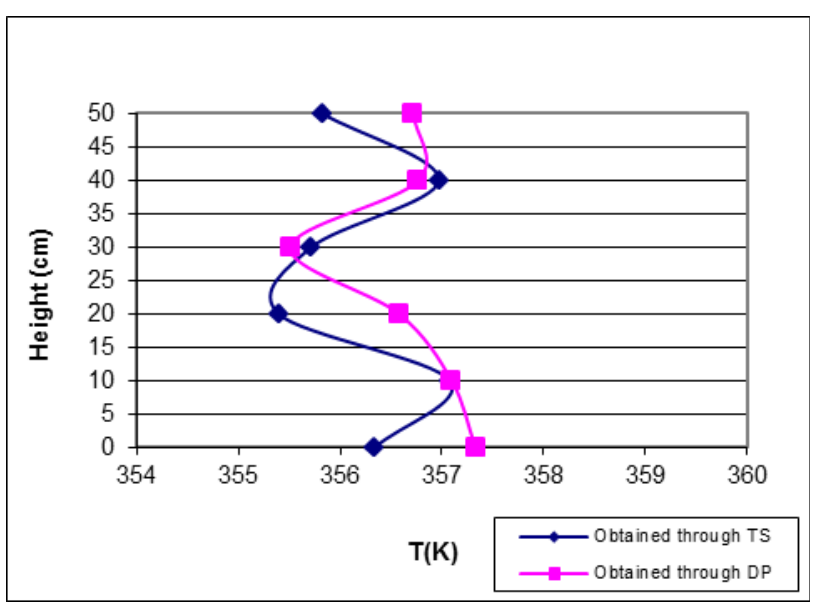

Fig. 6. Comparison of temperatures obtained through DP and TS (outer layer, coil 2). 


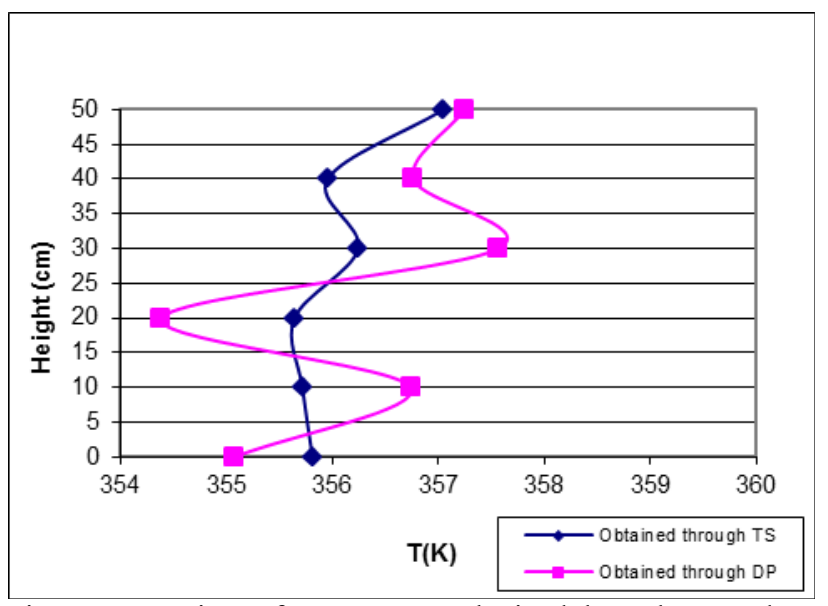

Fig. 7. Comparison of temperatures obtained through DP and TS (inner layer, coil 2).

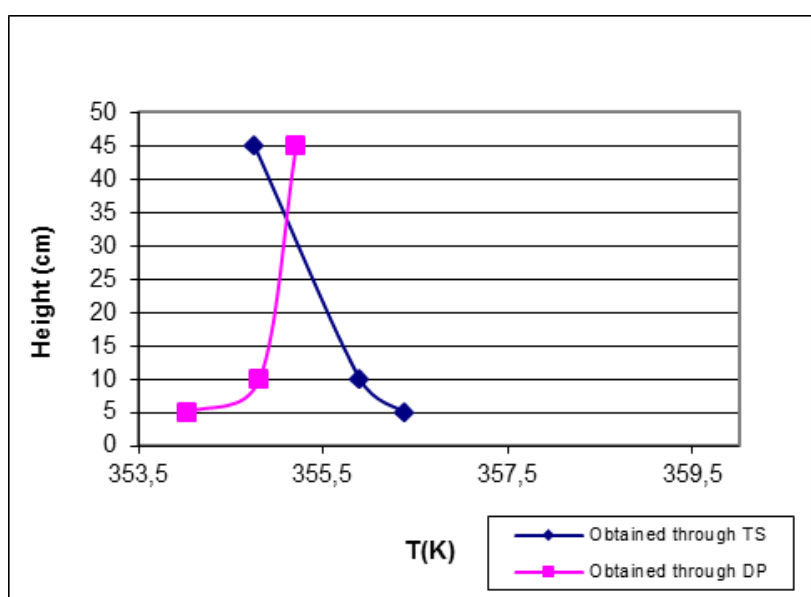

Fig. 8. Comparison of temperatures obtained through DP and TS (outer layer, coil 1).

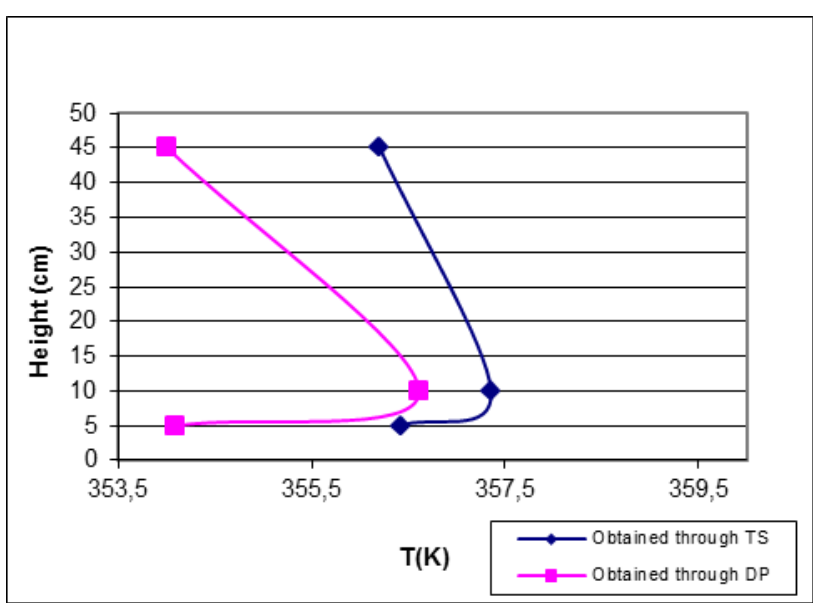

Fig. 9. Comparison of temperatures obtained through DP and TS (inner layer, coil 1).

\section{5.- Conclusions}

This work has carried out a postmortem temperature estimation of a distribution transformer. The study involved the evaluation of paper condition in the surface layer of the high voltage coils that insulates the machine. Two properties of the paper have been analyzed, providing information about its level of degradation. The first is the degree of polymerization and the second is the tensile strength index. Previous postmortem studies had only used the degree of polymerization for determining the status of the dielectric paper. The aim of this study was to test the suitability of the tensile strength index to perform postmortem studies. To do so the temperature distribution is obtained from the tensile strength index along the transformer windings. Once obtained this temperature distribution, it is compared with that determined from the degree of polymerization of the same paper samples. 
The comparison of the two temperature distributions showed that the maximum difference for the same point is less than $3.3 \mathrm{~K}$. There are some points where the values obtained from DP and TS were almost coincident. The two methods have proven valid for postmortem study of transformers, the tensile strength index being a more reliable and repeatable indicator. The test giving the tensile stress is carried out more quickly than the one serving to obtain the degree of polymerization. While the first one may take 10 minutes per sample, the second one usually takes a few days per sample, and it is also much more laborious to obtain. Furthermore, the paper sample required to perform the degree of polymerization test is very small compared to the one required by the standard in the case of the tensile test, where the samples size must be $15 \times 250 \mathrm{~mm}$. This sample size is very difficult to obtain in postmortem studies, because the paper is very weathered and is very fragile. The latter would be the main disadvantage of this type of test.

\section{Acknowledgement}

The authors wish to express their sincere appreciation to the company GE Energy Power Systems Spain SA (Fierro Service Center) for putting at our disposal the transformer studied and the necessary support to carry out this work.

\section{References}

[1] P.S. Georgilakis, Spotlight on modern transformer design. Springer: London, UK, (2009).

[2] CIGRÉ, Transformer failure investigation and postmortem analysis, (2011).

[3] P. Jarman, R. Hooton, L. Walker, Q. Zhong, T. Ishak, Z. Wang, Transformer life prediction using data from units removed from service and thermal modelling, A2 212 CIGRE, (2010).

[4] P. Jarman, Z.D. Wang, Q. Zhong, T. Ishak, End-of-life modelling for power transformers in aged power system networks, 6th Southern Africa Regional Conference, Cape Town, Southern Africa CIGRE, (2009).

[5] D. Susa, K.B. Liland, L. Lundgaard, G. Vardal, Generator step-up transformer postmortem assessment, Euro. Trans. Electr. Power, 21 (2011) 1802-1822. doi: 10.1002/etep.544

[6] T.A. Prevost, H.P. Gasser, C. Krause, The value of postmortem investigations for the condition assessment of power transformers, Weidmann-ACTI Inc. Sixth Annual Technical Conference (2007) 111.

[7] IEEE Guide for Failure Investigation, Documentation, and Analysis for Power Transformers and Shunt Reactors, (1991).

[8] Ageing of Cellulose in Mineral-Oil Insulated Transformers, CIGRE Brochure 323 (2007).

[9] R. Sanghi, Chemistry behind the life of a transformer, Springer, 8 (2003) 17-23. doi: 10.1007/ BF02837865

[10] T. Leibfried, M. Jaya, N. Majer, M. Schäfer, M. Stach, S. Voss, Postmortem Investigation of Power Transformers - Profile of Degree of Polymerization and Correlation With Furan Concentration in the Oil, IEEE Trans. Power Del., 28 (2013) 886-893, doi: 10.1109/TPWRD.2013.2245152.

[11] C. Homagk, K. Mossner, T. Leibfried, Investigation on degradation of power transformer solid insulation material, Annual Report Conference on Electrical Insulation Dielectric Phenomena, (2008) 7578.

[12] H.C. Sun, Y.C. Huang, C.M. Huang, A Review of Dissolved Gas Analysis in Power Transformers, Energy Procedia, 14 (2012) 1220-1225. doi: 10.1016/j.egypro.2011.12.1079.

[13] B. Pahlavanpour, M. Augusta, G. Martins, A. De Pablo, Experimental investigation into the thermal ageing of Kraft paper and mineral insulating oil, IEEE International Symposium on Electrical Insulation, (2002) 341-345. doi: 10.1109/ELINSL.2002.995946

[14] T. Leibfried, U. Thieb, I. Hohlein, B. Breitenbauch, T. Lainck, J. Leibner, S. Truant, Profile of water content and degree of polymerisation in the solid insulation of power transformers, IEEE International Symposium on Electrical Insulation, (2004) 109-112. doi: 10.1109/ELINSL.2004.1380475.

[15] M.A. Taghikhani, A. Gholami, Temperature distribution in ONAN power transformer windings with finite element method, Eur. Trans. Electr. Power, 19 (2009) 718-730. doi: 10.1002/etep.251.

[16] J. Zhang, X. Li, M. Vance, Experiments and modeling of heat transfer in oil transformer winding with zigzag cooling ducts, Appl. Therm. Eng., 28 (2008) 36-48. doi: 10.1016/j.applthermaleng.2007. 02.012 .

[17] N.E. Wakil, N.C. Chereches, J. Padet, Numerical study of heat transfer and fluid flow in a power transformer, Int. J. Therm. Sci., 45 (2006) 615-626. doi: 10.1016/j.ijthermalsci.2005.09.002. 
[18] F. Torriano, P. Picher, M. Chaaban, Numerical investigation of 3D flow and thermal effects in a disc-type transformer winding, Appl. Therm. Eng., 40 (2012) 121-131. doi: 10.1016/j.applthermaleng. 2012.02.011

[19] F. Torriano, P. Picher, M. Chaaban, Numerical study of parameters affecting the temperature distribution in a disc-type transformer winding, Appl. Therm. Eng., 30 (2010) 2034-2044. doi:

10.1016/j.applthermaleng.2010.05.004

[20] A. Skillen, A. Revell, H. Iacovides, W. Wu, Numerical prediction of local hot-spot phenomena in transformer windings, Appl. Therm. Eng., 36 (2012) 96-105. doi:10.1016/j.applthermaleng.2011.11.054. [21] A.M. Emsley, G.C. Stevens, Review of chemical indicators of degradation of cellulosic electrical paper insulation in oil-filled transformers, IEE Proceedings on Science Measurement and Technology, 141 (1994) 324-334. doi: 10.1049/ip-smt:19949957.

[22] C. Krause, Power transformer insulation - history, technology and design, IEEE Trans. Dielectr. Electr. Insul., 19 (2012) 1941-1947. doi: 10.1109/TDEI.2012.6396951.

[23] M. Koch, S. Tenbohlen, D. Giselbrecht, C. Homagk, T. Leibfried, Onsite, online and postmortem insulation diagnostics at power transformers, CIGRÉ (2007).

[24] C. Homagk, K. Mossner, T. Leibfried, Investigation on degradation of power transformer solid insulation material, Conference on Electrical Insulation and Dielectric Phenomena CEIDP, Annual Report, (2008) 75-78.

[25] M.A. Martins, M. Fialho, J. Martins, M. Soares, M. Cristina, R.C. Lopes, H.M.R. Campelo, Power transformer end-of-life assessment-Pracana case study, IEEE Elect. Insul. Mag., 27 (2011) 15-26. doi: 10.1109/MEI.2011.6059980.

[26] N. Lelekakis, G. Wenyu, D. Martin, J. Wijaya, D. Susa, A field study of aging in paper-oil insulation systems, IEEE Elect. Insul. Mag., 28 (2012) 12-19. doi: 10.1109/MEI.2012.6130527.

[27] L.E. Lundgaard, W. Hansen, D. Linhjell, T.J. Painter, Ageing of oil-impregnated paper in power transformers, IEEE Trans. Power Del., 19 (2004) 230-239. doi: 10.1109/TPWRD.2003.820175

[28] T.V. Oommen, L.N. Arnold, Cellulose insulation materials evaluated by degree of polymerization measurements, $15^{\text {th }}$ Elect./Electron. Insulation Conf., (1981) 257-261.

[29] H.P. Moser, V. Dahinden, Transformer board II, CH-8640 Rapperswil, (1987) S. 153/154.

[30] ASTM D4243-99(2009) Standard test method for measurement of average viscometric degree of polymerization of new and aged electrical papers and boards.

[31] IEC 60641-2(2004) Pressboard and press paper for electrical purposes - Part 2: Methods of tests

[32] ISO 1924-2 (2008) Paper and board - Determination of tensile properties - Part 2: Constant rate of elongation method

[33] R.J. Heywood, The Degradation Models of Cellulosic Transformer Insulation, Thesis, (1997). URL: http://epubs.surrey.ac.uk/id/eprint/2129 (Last access: August 2013) 